\author{
Eliza Matusiak \\ Uniwersytet Łódzki \\ ORCID: 0000-0003-2455-0245
}

\title{
Alexa, play The Inspection Chamber. O interaktywnym słuchowisku produkcji BBC w obliczu zwrotu audytywnego
}

\begin{abstract}
Streszczenie
Doba mediów interaktywnych, poszukiwanie alternatywnych metod otwarcia dzieła prowadzi do zaistnienia utworów u pełni audialnych, jednak interaktywnych. Poustają słuchowiska bazujące na „polu zdarzeń”, w ramach którego odbiorca podejmuje interakcje z dziełem. Celem artykułu jest uskazanie nowego podejścia twórczego w sztuce audialnej, omówienie specyfiki interaktywnego słuchowiska The Inspection Chamber produkcji BBC w kontekście zurotu audytywnego oraz poznawczo-edukacyjnego potencjału dzieła.
\end{abstract}

Słowa kluczowe: słuchowisko, sztuka audialna, sztuka interaktywna, zwrot audytywny, zwrot edukacyjny.

\begin{abstract}
Alexa, play The Inspection Chamber. About interactive radio drama by $B B C$ in the face of audio turn

Abstract

Radio, in the era of new media convergence, has found a perfect place in the space of interactive media. Acceptance practices of audience have changed, because multimedia imply asynchronism, individualization, hypertextuality. The sound environment, the audiosphere, becomes the space of experience, the field of interactive reception events in which action is a constitutive element. In addition, artistic broadcasting gains new media, with the help of which it is possible to participate interactively in the course of the phonic story, which raises questions about the transformation of audio art in the culture of interaction. The listeners gained the possibility of individually adapting the audio content to their own needs and requirements, also in the art of sound. In this article, the considerations will be focused around the specifics of the interactive audio play The Inspection Chamber produced by BBC. The aim of the article is to indicate a new creative approach taking place in the audio art and to characterize its features on the example of The Inspection Chamber in the context of the audio turn. The basis for the goal is to answer research questions about the place of sound art in interactive culture, the specificity of interactive audio theatre.
\end{abstract}

Keywords: radio art, interactive art, sound art, interactive radio, new media. 


\section{Wprowadzenie}

Radio, w dobie nowomedialnej konwergencji ${ }^{1}$, doskonale odnalazło się w przestrzeni mediów interaktywnych. Zmianie uległy praktyki odbiorcze², bowiem wraz z „erą multimedialną, która przyniosła z sobą asynchronizm, indywidualizację, programowalność i hipertekstualność”3 słuchacze zyskali możliwość indywidualnego dostosowywania treści audialnych do własnych potrzeb i wymagań. Praktyki te znalazły odzwierciedlenie nie tylko $w$ ofercie programowej stacji radiowych, ale także - w sztuce audialnej o interaktyunym, hipertekstualnym charakterze, czyniąc słuchacza niejako elementem, cząstką dzieła. Artykuł podejmujący analizę problematyki odbiorcy jako uczestnika kultury i jej tekstów Anna Kowalska otwiera w słowach:

gwałtowne przemiany uspółczesnej sceny komunikacyjnej prowokują do ważnych pytań o zmianę miejsca literatury w kulturze. Sytuacja literatury ulega ciągłej i nieuchronnej transformacji - literatura «zyskuje nowe nośniki, wkracza na nowe obszary, znajduje nowych odbiorców» ${ }^{4}$.

W dalszej części rozważań badaczka, odwołując się do słów Stefana Żółkieuskiego, zastanawia się, co odbiorcy „robią z literaturą”. W polu rozuażań skupionych wokół sztuki radia warto zastanowić się, co słuchacze „robią ze słuchowiskiem” (i będą mogli „robić”). Staje się ono bowiem przestrzenią dośuiadczenia, polem zdarzeń interaktywnego odbioru, w którym owo „robienie”, działanie, stanowi element konstytutywny. Ponadto radiofonia artystyczna ${ }^{6}$ zyskuje nowe nośniki, za pomocą których możliwe jest interaktywne uczestnictuo w biegu opowieści fonicznej, co powołuje do pytań o transformacje sztuki audialnej w kulturze interakcji.

Jak zauważył Walter J. Ong,

wzrok wyodrębnia, dźwięk wciela. O ile wzrok sytuuje obserwatora na zewnątrz tego, co ogląda, u pewnej odległości, o tyle dźuięk ulewa się w słuchacza [...]. W danym momencie widzenie dociera do istoty ludzkiej z jednego kierunku; by spojrzeć na pokój lub na krajobraz, muszę przenieść oczy z jednego na drugi. Tymczasem kiedy słucham, otrzymuję

${ }^{1}$ O genezie i znaczeniu pojęcia „konwergencja”, zob. H. Jenkins, Kultura konwergencji. Zderzenie starych i nowych mediów, Wydawnictwa Akademickie i Profesjonalne, Warszawa 2007, s. 9. ${ }^{2}$ O nowych praktykach odbiorczych w perspektywie zmian technologicznych stacji radiouych zob. P. Czarnek-Wnuk, Tradycyjne rozgłośnie radiowe $w$ mediach społecznościowych, „Media Kultura - Komunikacja Społeczna" 2016, nr 12/4, s. 41-50.

${ }^{3}$ K. Albińska, Kilka uwag o przeobrażeniach środowiska medialnego wspótczesnego radiosłuchacza. Szkic przeglądowy, „Media i Społeczeństwo: medioznawstwo, komunikologia, semiologia, socjologia mediów" 2011, nr 1, s. 77.

${ }^{4}$ A. Kowalska, Uczestnik kultury - nowy czytelnik [w:] Między sztuka a codziennościa. W stronę nowej syntezy (1), red. M. Hopfinger, Z. Ziątek, T. Zukouski, Instytut Badań Literackich PAN, Warszawa 2016, s. 31.

${ }^{5}$ Ibidem.

${ }^{6}$ O radiofonii artystycznej i literaturze audialnej, zob. J. Bachura-Wojtasik, Literatura audialna między fikcja a niefikcja. "Upowieściowienie” dokumentu a narracje fikcyjne [w:] Między sztuka a codziennościa..., op. cit., s. 184-212. 
sygnały dźwiękoue jednocześnie ze wszystkich kierunków na raz: jestem u centrum suego słyszalnego świata, który mnie spowija?

Nad poszukiwaniem dróg „wcielenia” słuchacza w opowieść audialną, uczestniczenia w toku jej akcji tak, by wyróżnione przez Onga sygnały dźwiękowe sprzęgły się z interakcją, zastanawiała się podczas konferencji Next Radio ${ }^{8}$ Nicky Birch z agencji Rosina Sound. Pytania formułowane przez Birch padły niejako post factum, gdy ta znała na nie odpowiedź, bowiem BBC we uspółpracy właśnie z studiem Rosina Sound stworzyli interaktywne słuchowisko The Inspection Chamber. Moim celem jest uskazanie nowego podejścia twórczego zachodzącego w sztuce słuchowiskowej oraz scharakteryzowanie jego cech na przykładzie The Inspection Chamber w kontekście zurotu audytywnego. U podstaw postawionego celu leżą odpowiedzi na pytania badaucze o miejsce sztuki dźwięku w kulturze interaktywnej, o specyfikę interaktywnego teatru audialnego. W formułowaniu wniosków posłużę się metodą jakościową, właściwą metodyce badań nad mediami oraz sztuką mediów - analizą ${ }^{9}$ Analizie jakościowej została poddana zawartość słuchowiska interaktywnego - jego specyfika i wyróżniki znajdujące swe źródło w tworzywie fonicznym tradycyjnego słuchowiska radiowego, rozpatrywane jednak z perspektywy interaktywnego charakteru dzieła.

\section{Dźwiękowe środowisko człowieka a zwroł audyływny}

U początków rozważań nad interaktyunymi dziełami audialnymi obligatoryjnie należy przywołać pojęcie konstytutyune dla sztuki fonicznej, czyli audiosferę ${ }^{10}$. Audiosfera, jak podaje Maryla Hopfinger, to „dźwiękowe środowisko ludzi, [które] zmienia się wraz z przekształceniami cywilizacyjnymi, rozwojem technologii rejestrowania, przetwarzania, i kreowania dźwięku, dostosowuje się do przemian kultury"11. Niebagatelna w zderzeniu praktyk odbiorczych ze zmianami kultury i przemianami technologii jest rola odbiorcy „w procesie komunikacji za pomocą dźwięku, jego wrażeń, przeżyć, emocji wywoływanych poprzez dźwięk, muzykę, ciszę"12. Audialny tekst kultury o interaktyunej specyfice zdaje się nader mocno włączać słuchacza u proces dźwiękowej komunikacji, komunikacji z narzędziem, komunikacji z dziełem ${ }^{13}$. Jak konstatował Wojciech Siwak, „większa jest w percepcji audiosfery rola poznania intuicyjnego,

\footnotetext{
W.J. Ong, Oralność i piśmienność. Stowo poddane technologii, przeł. J. Japola, Redakcja Wydaunictw Katolickiego Uniwersytetu Lubelskiego, Lublin 1992, s. 105.

${ }^{8}$ Fragment konferencji Next Radio, podczas którego Nicky Birch porusza wątki procesu twórczego podczas pracy nad The Inspection Chamber jest dostępny pod adresem: https:// wuw.youtube.com/watch?v=pj6WhXEGq6g (dostęp: 08.11.2019).

${ }_{9}$ Zob. M. Lisouska-Magdziarz, Metodologia badań nad mediami - nurty, kierunki, koncepcje, nowe wyzwania, „Studia Medioznawcze” 2013, nr 2, s. 27-42.

${ }_{10}$ Termin powołała do istnienia u dyskursie akademickim M. Gołaszeuska. Zob. Eadem, Estetyka pięciu zmysłów, Wydawnictwo Naukowe PWN, Warszawa-Kraków 1997.

${ }^{11}$ M. Hopfinger, Literatura i media, Oficyna Naukowa, Warszawa 2010, s. 141.

12 J. Bachura-Wojtasik, Literatura audialna między fikcją..., op. cit., s. 189.

${ }^{13}$ Wątek ten rozwijam u dalszej części tekstu.
} 
afektyunego” ${ }^{14}$, a u doświadczaniu utworów sztuki dźwiękowej istotą jest „emotywne [weń] zanurzanie"15. Dzieła nielinearnej sztuki audialnej u suych podstaw za cel obierają możliwość immersyjnego ${ }^{16}$ zanurzenia się odbiorcy w bieg swej fabuły, za jego bowiem sprawą możliwa staje się konkretyzacja opowieści. Toteż interaktywne słuchowisko The Inspection Chamber może stanowić egzemplifikację nowej składowej przestrzeni audiosfery dostosouującej się do przemian technologicznych i kulturowych.

Odsłuch interaktywnego dzieła produkcji BBC i studia Rosina Sound jest umożliwiony poprzez inteligentny głośnik Amazon Echo. Wirtualny asystent, Alexa, reaguje na komendy głosowe użytkownika głośnika i rozpoczyna opowieść. Interakcje na linii utwór-słuchacz zachodzą dzięki „silnikowi historii”, który jest uruchamiany poprzez polecenia uydawane wirtualnemu asystentowi. Hyunji Chung wraz z pozostałymi autorami artykułu Alexa, Can I trust you? ${ }^{17}$ nadmieniają:

inteligentni wirtualni asystenci (IVAs) otwierają nowy świat; świat, w którym można rozmawiać z urządzeniem tak, jakby było człowiekiem. Urządzenie wykona zadanie, o które prosisz. Na przykład, kiedy się obudzisz, zapytasz: «Hej, co jest w moim harmonogramie na dzisiaj?»; zanim opuścisz dom: «Hej, co z moim transportem?». [...]. IVAs mogą jawić się jako nowe i tajemnicze dla niektórych konsumentów, ale są obecne na rynku. Według analizy Gartner ${ }^{18}$, rynek IVA osiągnie wartość 2,1 miliarda dolarów do 2020 roku $^{19}$.

Dynamiczny, szeroko zakrojony rozwój rynku głosouych asystentów może stanowić nie tylko jeden z przykładów, jak technologia przenika do codziennego życia człowieka, mając je usprawnić, czynić łatwiejszym i bardziej zorganizowanym. Immanentny związek tego rodzaju rozwiązań technologicznych z wykorzystaniem zmysłu słuchu ${ }^{20}$ może uskazywać na jeden z przejawów zurotu audytywnego. Jan Pleszczyński w suych

${ }^{14}$ W. Siwak, Audiosfera na przetomie stuleci [w:] Nowe media w komunikacji spolecznej w XX wieku. Antologia, red. M. Hopfinger, Oficyna Naukowa, Warszawa 2005, s. 165.

15 Ibidem.

${ }^{16}$ Pojęcie immersji oznacza „zdolność do wywołania efektu «zanurzenia» odbiorcy u tego rodzaju [rzeczywistości wirtualnej] świecie". Zob. J.Z. Szeja, Tworzenie rzeczywistości wirtualnej [w:] Między sztuka a codziennościa..., op. cit., s. 504. Sue rozważania poświęciła immersji m.in. K. Prajzner [w:] Tekst jako świat i gra. Modele narracyjności w kulturze wspótczesnej, Wydaunictwo Uniwersytetu Łódzkiego, Łódź 2009.

${ }_{17}$ Pozostali autorzy tekstu to: Michaela Iorga, Jeffrey Voas oraz Sangjin Lee, https://wuw.ncbi. nlm.nih.gov/pmc/articles/PMC5714311 (dostęp: 08.11.2019).

${ }_{18}$ Newsroom Gartner. Gartner Says Worldwide Spending on VPA-Enabled Wireless Speakers Will Top \$2 Billion by 2020. https://www.gartner.com/newsroom/id/3464317, cyt. za Hyunji Chung $\mathrm{i}$ in.

${ }^{19}$ Ibidem. Tłum. własne [E.M.]. Zapis oryginalny: „Intelligent Virtual Assistants (IVAs) open a new world, a world where you can talk to a machine as if it were a human and the machine will perform the work you request. For example, when you wake up, "Hey, what's on my schedule for today?" Before you leave the house, "Hey, what's my commute?" [...]. IVAs may be new and mysterious to some consumers, but they are in the market place today. Gartner has said that the IVA market will reach $\$ 2.1$ billion by 2020".

${ }^{20}$ Zob. W. Krzemińska, A. Krzemińska, Ekspansja nowych form komunikacyjnych w środowisku dźwiękowym człowieka [w:] Przestrzenie wizualne i akustyczne człowieka. Antropologia audiowizualna jako przedmiot i metoda badań, red. A. Janiak, W. Krzemińska, 
rozważaniach dotyczących zurotu fonicznego stuierdza, że ich podstawę stanowi „onto-epistemologiczny model, który nazywa «wędrującym trójkątem»”21. Eksplikując ów termin, Pleszczyński pisze:

w technicznym języku socjologii i filozofii wierzchołki «uędrującego trójkąta» odpowiadają podmiotowi jednostkowemu, podmiotowi zbiorowemu i «śuviatu». [...] W nawiązaniu do znanej i utrwalonej w filozofii nauki terminologii Karla Poppera można, w pewnym uproszczeniu, pouiedzieć, że u modelu «uędrującego trójkąta» «świat» jest Popperouskim «pieruszym światem», «człouiek» drugim, a «kultura» trzecim. [...] Tutaj precyzja terminologiczna nie jest aż tak istotna, więc wygodniej mówić po prostu o człowieku, kulturze i śuiecie ${ }^{22}$.

Badacz odnosi istotę wędrującego trójkąta do specyfiki ludzkiego poznania, które zausze jest zaangażowane w jakieś konteksty kulturowe. Elementy wędrującego trójkąta są wobec siebie koherentne, nierozerwalne. Model, uskazuje Pleszczyński,

stanowi onto-epistemologiczną całostkę, co oznacza, że jego elementy są rozróżnialne, ale nierozdzielne i wzajemnie się warunkują. Słowo wędrujący uskazuje na dynamiczny charakter relacji: gdy zmienia się kultura, zmienia się też człowiek i świat, zmiany u świecie skutkują zmianami w człowieku i w kulturze, zmiany w człowieku mają upłyu na świat i kulturę. Gdyby model ten przedstawić w postaci animowanej grafiki, wierzchołki trójkąta byłyby ruchome i on sam nieustannie by się zmieniał, ale nadal pozostawał trójkątem²3.

Ponadto punkt ciężkości wędrującego trójkąta został położony na proces komunikacji, stanowi ona bowiem konstytutywny czynnik upisanego w kulturę ludzkiego poznania.

Dzięki komunikacji - uzupełnia Pleszczyński - ludzie się porozumiewają i mają dostęp do kultury, a za jej pośrednictuem do świata. Komunikacja jest więc relacją więziotwórczą i poznawczą. Ludzka wiedza o śuiecie zausze jest filtrowana przez kulturę, zaś media, jako narzędzia komunikacji, nadają i określają jej formę. Współczesne media bazują na zaawansowanych technologiach, więc normy technologiczne w coraz większym stopniu wypierają i zastępują w komunikacji reguły kulturowe; w literaturze to zjawisko nazywane bywa hipermediacją ${ }^{24}$.

A. Wojtasik-Tokarz, Wydawnictuo Naukowe Dolnośląskiej Szkoły Wyższej Edukacji TWP, Wrocław 2007, s. 110-127.

${ }^{21}$ J. Pleszczyński, Dźwięk i muzyka: między racjomorficznościa a racjonalnościa [w:] Media multimodalne. Zagadnienia ogólne i teoretyczne. Multimodalność mediów drukowanych, t. 1, red. I. Hofman, D. Figura-Kępa, Wydawnictwo Uniwersytetu Marii Curie-Skłodouskiej, Lublin 2018, s. 36.

${ }^{22}$ Ibidem, s. 37.

${ }^{23}$ Ibidem.

${ }^{24}$ Ibidem. 


\section{Odsłuch uczestniczący i interakływność słuchowiska}

Pojęcie wędrującego trójkąta w kontekście zurotu audytywnego może stanowić podstawę do rozważań skupionych wokół interaktywnej sztuki audialnej. Egzemplifikację narzędzia komunikacji, które umożliwia percepcję interaktywnego tekstu kultury, może stanowić Amazon Echo z wbudowaną weń Aleksa. W drodze odbioru The Inspection Chamber dochodzi do nowej formy komunikacji. Użytkownik komunikuje się z wirtualnym asystentem. Przy jego pomocy uruchamia słuchowisko interaktywne, z którym, poprzez uydawanie uskazówek głosouych, porozumiewa się, ingerując w bieg zdarzeń w śuiecie przedstawionym. Komunikacja zostaje zapośredniczona technologicznie, jednak nie dochodzi do komunikacji na linii człowiek - narzędzie - człowiek, a na linii słuchacz - narzędzie (wirtualny asystent) - dzieło (słuchowisko). Tym samym komunikacja z urządzeniem umożliwia komunikację z dziełem sztuki audialnej, która nie była dotąd możliwa dla odbiorców sztuki radiowej. Zwrot audytywny, zachodzący w oparciu o interaktywne narzędzia technologiczne, pozwala kierować dyskurs radioznawczy również u stronę rozważań nad aspektami poznawczymi umożliwionymi poprzez odbiór uczestniczący.

Interaktywna opowieść audialna nie niesie bowiem za sobą jedynie walorów estetycznych wynikających z obcowania ze sztuką. Odsłuch uczestniczący daje szansę na rozwój poznawczy, wymaga bowiem ciągłego zaangażowania. Ingerowanie w bieg historii świata przedstawionego stanowi niejako egzemplifikację zabawy formą. The Inspection Chamber nie jest opowieścią, w przestrzeń której odbiorca może włączać ułasne, przezeń stworzone elementy opowieści, jednak potencjalnych dróg odsłuchu jest na tyle wiele, by możliue stało się wielokrotne modyfikowanie formy i ostatecznego wybrzmienia słuchowiska. Zabawa formą sztuki interaktywnej stanowi czynnik angażujący, immersyjny. Fred Rogers i Hedda Sharapan w swym artykule poświęconym znaczeniu zabawy nadmienili, że:

zabawa ${ }^{25}$ jest wyrazem naszej kreatywności; a kreatyuność [...] jest podstawą naszej zdolności uczenia się, radzenia sobie i bycia kimkolwiek jesteśmy. Dla mnie zabawa jest procesem odnajdywania nouych kombinacji dla tego, co znane - kombinacji, które mogą przynieść nowe formy ekspresji, nowe intencje, nowe odkrycia i nowe rozwiązania ${ }^{26}$.

\footnotetext{
${ }_{25}$ Badacze odnieśli się w suych konstatacjach do znaczenia zabauy w rozwoju dzieci. Jednakże kreatyuny, uczestniczący odbiór i zabawa formą dzieła sztuki (także audialnej) jawią się jako pozbawione ograniczeń, również wiekowych, a owa obserwacja zdaje się wpisywać w podstawy sztuki interaktywnej jako sztuki poszukującej nowych kombinacji, nowych form ekspresji.

${ }^{26}$ F. Rogers, H. Sharapan, Special Issue on Counseling and Children's Play, „Elementary School Guidance \& Counseling” 1993, vol. 28, no. 1, s. 5. Tłum. własne [E.M.]. Zapis oryginalny: „Play is an expression of our creativity; and creativity [...] is at the very root of our ability to learn, to cope, and to become whatever we may be. To me, play is the process of finding new combinations for know things - combinations that may yield new forms of expression, new intentions, new discoveries, and new solutions".
} 
Zabawa rozumiana jako proces poszukiwania nowych kombinacji, połączeń, może stanowić niejako klucz do pojmowania, czym słuchowisko interaktywne w istocie jest. Stanowi ono przykład formy skończonej, w ramach której słuchacz poprzez sue decyzje poszukuje nowych ścieżek odsłuchu, nowych rozwiązań fabularnych. Jak dostrzegł Ryszard Kluszczyński,

artysta-autor [utworu interaktywnego] przestaje być jedynym twórcą sensu dzieła, które uspółtworzone jest $\mathrm{w}$ tej nowej sytuacji przez odbiorcę $\mathrm{w}$ procesie interakcji z artefaktem. Zadaniem artysty staje się stworzenie tego właśnie artefaktu: układu-kontekstu, w którym odbiorca/interaktor konstruuje przedmiot tego doświadczenia i jego sens ${ }^{27}$.

Przestrzeń słuchowiska interaktywnego jest zatem polem zdarzeń, stworzonym przez artystów układem-kontekstem, w ramach którego słuchacz konstruuje imaginatywną rzeczyuistość opowieści audialnej. Ponadto, odwołując się nadal do tez Kluszczyńskiego, należy odnotować, że słuchowisko klasyczne ma naturę preinteraktyuną, bowiem „nie można niczego zmienić $w$ budowie dzieła, ani w jego semantyce" ${ }^{28}$. W przypadku audialnego utworu interaktywnego, „[i]nteraktywność staje się - zauważa Kluszczyński wewnętrzną zasadą dzieła, a odbiorca - jeśli pragnie dokonać jego konkretyzacji - musi podjąć działania, w wyniku których zostanie ukształtowany przedmiot jego percepcji”29. Słuchacz ergodycznego teatru wyobraźni poprzez interaktyune zabawy formą dzieła uczestniczy w dziele-wydarzeniu. Nie oznacza to jednak, że słuchowisko interaktywne dalekie jest od swych pierwotnych wyznaczników genologicznych.

\section{Dramaturgia i tworzywo The Inspection Chamber}

Elżbieta Pleszkun-Olejniczakowa w swych refleksjach o sztuce audialnej konstatowała, że

[...] słuchowiska oryginalne, [to] teksty pisane specjalnie dla radia, tworzone od razu z myślą o tym medium - z uuzględnieniem jego możliwości, ale i ograniczeń. [...] Trzeba też pamiętać - uzupełniała radioznawczyni - że scenografię, kostiumy i rekwizyty tworzą wyłącznie dźwięki ${ }^{30}$.

Wobec tego w słuchowisku interaktywnym obligatoryjne staje się uwzględnienie dodatkowego medium, które stanowi koherentny czynnik dla zaistnienia interaktywnej opowieści. Konkretyzowanie się The Inspection Chamber umożliwiają interakcje z wirtualnym asystentem. Specyfika tego rodzaju rozwiązania technologicznego determinuje innowacyjne przekształcenia dramaturgiczne, które stały się immanentnym czynnikiem uwzględnianym przez tuórców podczas pisania scenariusza audialnego

${ }_{27}$ R.W. Kluszczyński, Film-wideo-multimedia. Sztuka ruchomego obrazu w erze elektronicznej, Wydawnictuo Rabid, Kraków 2002, s. 31.

${ }^{28}$ Ibidem, s. 215.

${ }^{29}$ Ibidem, s. 26.

${ }^{30}$ E. Pleszkun-Olejniczakowa, Muzy rzadko się do radia przyznają. Szkice o stuchowiskach i reportażach radiowych, Primum Verbum, Łódź 2012, s. 53. 
dramatu. Język właściwy sztuce słuchowiskowej pojmowany jako udźwiękowione słowo wsparte o gest foniczny i efekty kuchni akustycznej oraz muzykę $e^{31}$ bezwarunkowo został dostosowany do nowej, ergodycznej struktury opowieści i interaktywnych dróg odbioru. Henry Cooke, producent The Inspection Chamber, określa słuchowisko jako „interaktywną komedię science fiction inspirowaną utworami Douglasa Adamsa i Franza Kafki" ${ }^{2}$. Fabuła The Inspection Chamber traktuje o zadaniu, jakie stoi przed parą naukowców - pracują oni nad katalogowaniem nieznanych dotąd obiektów poruszających się w przestrzeni kosmicznej. W pracy pomaga im komputer, Dave. Jednym z wymagających opisania bytów jest słuchacz, którego Dave wraz z naukowcami muszą przepytać w taki sposób, by możliwa stała się prawidłowa klasyfikacja gatunkowa i uzupełnienie opracouywanej przez lata bazy danych. Dave prowadzi słuchacza przez meandry dzieła od pierwszych jego sekund. Otwarcie opowieści uzupełnione zostało o instrukcję, w której użytkounik otrzymuje informacje o tym, że konieczne jest udzielanie odpowiedzi na zadawane przez postaci pytania oraz jak prawidłowo winien to czynić. Oczekiwanie na decyzję słuchacza jest sygnalizowane poprzez zaświecenie się diod znajdujących się w obudowie urządzenia. Każdorazowo, po upływie około dziewięćdziesięciu sekund uybrzmiewa pytanie, na które słuchacz musi odpowiedzieć, by opouieść wkroczyła na kolejny etap fabularny. Tym samym słuchacz staje się bohaterem historii, na której bieg ma upływ poprzez interaktyune decyzje.

W The Inspection Chamber można wyróżnić kilka typów artykułowanych przez komputer lub naukowców pytań. Obecne są pytania, które umożliwiają wybór odpowiedzi spośród wariantów zaproponowanych przez asystenta, np.: „Which of these do you indentify? a) humanoide, b) carrot, c) bird etc...?” lub „Dream or reality?”. Występują także pytania otwarte, podczas formułowania których nie zostają wymienione sugerowane odpowiedzi. Egzemplifikacje otwartych interlokucji stanowią pytania: „Are you ready to be inspected?” oraz „What do you call yourself?”. W przypadku tego rodzaju pytań ich istota nie leży u próbie uzyskania konkretnej odpowiedzi, a podtrzymaniu konwersacji, interakcji ze słuchaczem, co skutkuje wrażeniem immersyjnego zanurzenia w opowieść i faktycznego w niej udziału. Za sprawą otwartych dialogów dochodzi do swobodnej wymiany myśli. Odbiorca może odnieść urażenie, że rozmowa, choć surrealistyczna, zdaje się zbliżona do naturalnej konwersacji, co potencjalnie uzmaga zaangażowanie. Odbiorca The Inspection Chamber pozostaje zatem stale operatyunym słuchaczem-bohaterem opowieści otwartej na interakcje. Literaturoznawca Maciej Maryl wskazuje, że „zagadnienie otwarcia i zamknięcia tekstu można rozumieć przynajmniej dwojako: strukturalnie i semiotycznie. Strukturalnie każdy tekst musi być zamknięty jest to podstawowa ułasność, która odróżnia go od materiału pozatekstowego" ${ }^{33}$. Dzieło produkcji BBC, mimo otwarcia na interakcje, pozostaje strukturalnie zamknięte.

${ }^{31}$ O języku sztuki słuchowiskowej pisała J. Bachura-Wojtasik. Zob. Eadem, Odsłony wyobraźni. Wspótczesne stuchowiska radiowe, Wydawnictwo Adam Marszałek, Toruń 2012, s. 226-227.

${ }^{32}$ https://uww.bbc.co.uk/taster/pilots/inspection-chamber (dostęp: 08.11.2019).

${ }^{33}$ M. Maryl, Pozorne otwarcie hipertekstu. Model komunikacyjny hiperprozy, http://rcin.org. pl/Content/65710/WA248_84421_maryl-pozorne_o.pdf (dostęp: 08.11.2019). 
Słuchacz ingeruje w bieg opowieści, jednak posiada dostęp tylko do audialnych cząstek przygotowanych przez twórców w ramach Aarsethouskiego "pola zdarzeń, (event space), [które] zawiera u sobie wszystkie możliwe warianty opowiadania”34. Maryl dostrzega, że strukturalne ograniczenie tekstu kultury nie jest tożsame z zamknięciem $\mathrm{w}$ pojmowaniu semiotycznym ${ }^{35}$. Powołując się na spostrzeżenia, Jurija Łotmana postrzega semiotyczne otwarcie dzieła jako warunek obligatoryjny ${ }^{36}$. „Tekst, który dopuszcza jedną interpretację (lub też ograniczoną ich liczbę), po prostu nie jest dla tego badacza tekstem artystycznym" ${ }^{37}$ pisze Maryl.

W przypadku The Inspection Chamber wielość możliuych interpretacji nie ulega wątpliwościom. Jest to dzieło otwarte semiotycznie, lecz zamknięte strukturalnie, choć odbiorca odczuwa pozór, iluzję dwoistego otwarcia. Scenariusz słuchowiska nie został rozpisany tak, by zawierać $\mathrm{w}$ sobie wiele różnych historii determinowanych przez wybory słuchacza. Fabuła The Inspection Chamber oparta została o jedną historię, swoisty leitmotiv. Decyzje słuchacza prowadzą do wariantywnych sposobów przeżycia tejże opowieści, jednak stale jest to niepodlegająca znaczącym modyfikacjom historia ${ }^{38}$.

Zdaniem Nicky Birch ${ }^{39}$ obrane rozwiązanie dramaturgiczne umożliwia wykreowanie sytuacji przypominającej naturalną rozmowę, podczas której możliwe staje się budowanie immersyjnego doświadczenia. Poprzez brak nadmiernego rozbudowania opowieści starano się uniknąć niespójności fabularnych, które mogłyby zaburzyć poczucie immersyjnego zanurzenia, faktycznego uczestnictua w biegu wydarzeń. Zatem uybory dokonywane przez odbiorcę The Inspection Chamber są pozorne, nie upływają bowiem znacząco na akcję opowieści. Modyfikują jednak proces jej odsłuchu, obierając różnorodne ścieżki odbioru. Dzieło sztuki audialnej zostało skomponowane ze scen, wokół których rozgrywają się dialogi między słuchaczem a pozostałymi bohaterami opouieści. W przypadku powieści hipertekstualnej, co akcentował Mariusz Pisarski, pojedyncza cząstka opowieści jest zwana leksją bądź tekstonem. „Leksja (lub tekston) - pisał medioznawca - to względnie spójny i niepodzielny fragment tekstu będący podstawową jednostką hipertekstowej powieści. [...] Najczęściej - jest to dłuższy lub krótszy akapit rozbity na kilka paragrafów lub podakapity"40. Na drodze analogii należy odnotować, że pojedyncza scena osadzona pomiędzy pytaniami-interakcjami stanowi paralelną egzemplifikację, przeniesienie tekstonu do audialnego pola zdarzeń. Sceny interaktywnego teatru wyobraźni potencjalnie angażują odbiorcę. Historia jawi

\footnotetext{
34 E.J. Aarseth, Cybertekst. Spojrzenia na literaturę ergodyczną, przeł. M. Tabaczyński, Korporacja Ha!art, Kraków-Bydgoszcz 2014, s. 12.

35 Zob. M. Maryl, op. cit., online.

${ }^{36}$ Ibidem.

${ }^{37}$ Ibidem.

${ }^{38}$ Schemat konstrukcji dzieła został zamieszczony u rozmowie z twórcą słuchouiska, https:// wuw.bbc.co.uk/taster/pilots/inspection-chamber/inside-story (dostęp: 08.11.2019).

39 Zob. https://www.youtube.com/watch?v=pj6WhXEGq6g (dostęp: 08.11.2019).

${ }^{40}$ M. Pisarski, Hipertekst i hiperfikcja [w:] Liternet.pl, red. P. Marecki, Wydawnictwo Rabid, Kraków 2003, s. 288.
} 
się jako podatna na transformacje, co przypuszczalnie uzbudza poczucie sprauczości u słuchacza. Owo wrażenie nigdy nie zostanie wywołane w słuchowisku o tradycyjnej konstrukcji.

\section{Sytuacja komunikacyjna odbiorcy interaktywnego słuchowiska}

Przełożenie scenariusza tradycyjnego teatru wyobraźni do wymagań stawianych przez ergodyczny silnik historii sprawia, że zmianie ulega również sytuacja odbiorcza, w której znajduje się słuchacz. Dzieje się tak, ponieważ to decyzje odbiorcze, interakcje z utworem warunkują konkretyzowanie się dzieła, są gwarantem danego jego wykonania. Tym samym słuchacz z interpretatora staje się niejako użytkownikiem, uspółtwórcą znaczeń, a w przypadku utworu produkcji BBC - także bohaterem. Pisarski zurócił uwagę, że „wchodząc w interakcję z dziełem odbiorca stwarza coraz to inne semiotyczne sekwencje, konkretyzuje potencjalne na początku dzieła"41. The Inspection Chamber dla swego zaistnienia wymaga działań podejmowanych przez aktywnego słuchacza, który ma możliwość obrania wariantyunych ścieżek semantycznych historii. Co więcej, badacz akcentował, że „uszystkie rodzaje cybertekstu mają wspólną cechę, jest nią ergodyzm. Używa go [pojęcia ergodyzmu] do opisania takiego typu dyskursu, którego znaki wyłaniają się jak ścieżka wytworzona przez nietrywialny element dzieła" ${ }^{42}$. Bez wątpienia produkcja BBC jest przykładem ergodycznego tekstu kultury o nielinearnej konstrukcji ${ }^{43}$. Niemniej owo słuchowisko nie odbiega od wyróżników genologicznych tradycyjnego teatru wyobraźni. Dialogi zachodzące między słuchaczem a dziełem zostały wzbogacone o efekty kuchni akustycznej obecne w drugim planie akustycznym. Słyszalne szmery, szelesty, odgłosy urządzeń elektronicznych, kroków tworzą przestrzeń akustyczną audialnego tekstu kultury. Jak akcentowała Joanna Bachura-Wojtasik, „plany akustyczne niewątpliwie budują przestrzeń w słuchowisku, która okazuje się mimo suej jednowymiarowości przestrzenią trójuymiarową" ", co jest słyszalne w The Inspection Chamber. Wykorzystanie możliwości języka słuchowiska dopełnia narrację, czyniąc opowieść bardziej wiarygodną, co wzmaga jej immersyjny potencjał. „Narracja jest wypowiedzią nacechowaną ekspresywnie, o dużej silne sugestyuności”"45, co zdaje się szczególnie istotne w odniesieniu do dzieła, w którym walor sugestywności narracji umożliwia obieranie kolejnych ścieżek odsłuchu i eksplorowanie przestrzeni utuoru audialnego.

Espen Aarseth odnotował, że w dziełach o hipertekstualnym charakterze „zamiast jednej narracji i jednego opouiadania [...] mamy [...] do czynienia z bardziej fundamentalną

\footnotetext{
${ }^{41}$ M. Pisarski, Kartografowie i kompilatorzy. Pót żartem, pót serio o praktyce i teorii hiperfikcji $w$ Polsce [w:] Liternet.pl..., op. cit., s. 22.

${ }^{42}$ Idem, Hipertekst $i$ hiperfikcja..., op. cit., s. 285.

${ }^{43}$ O nielinearnej konstrukcji hipertekstu pisał M. Pisarski. Zob. ibidem.

44 J. Bachura, Odstony wyobraźni..., op. cit., s. 232.

${ }^{45}$ Ibidem, s. 260.
} 
strukturą: z polem zdarzeń (event space)"46. Fundament konstrukcyjny The Inspection Chamber stanowi opracowany przez twórców event space. Odbiorca jest jednym z bohaterów słuchowiska, suymi wyborami determinuje bieg historii, jednak dzieje się to u zaplanowanym polu zdarzeń, poza które wyjście nie jest możliwe. Słuchacz nie ma możliwości „pchnięcia” opowieści u dowolną fabularnie stronę, może jedynie obierać pewne fabularne warianty, które przyczyniają się do konkretyzowania danego odczytania dzieła. „Doświadczenie interaktywne - akcentował Ryszard Kluszczyński - jawi się [...] jako przeobrażenie intersubiektywnie egzystującego dyspozytyuu w indywidualnie konstruowane i wykonywane dzieło-wydarzenie" 4 .

\section{Podsumowanie}

Rozwiązania konstrukcyjne uykorzystane w tymże tekście kultury czynią The Inspection Chamber dyspozytywem, w ramach którego słuchacz podejmuje sue działania, doświadczenia interaktywne. Analizowane słuchowisko pojmuję jako hipertekstualno-audialną hybrydę o ergodycznym charakterze. Autorzy podjęli się wykreowania dyspozytywu, który przy pomocy głosowego asystenta pozwala na konkretyzowanie wariantywnych wątków i formułowanie nowych, odmiennych sensów w ramach pojedynczej opowieści. Stale toczące się zmiany technologiczne oraz poszukiwania nowych dróg otwarcia tekstów kultury prowadzą do powstawania dzieł takich właśnie jak The Inspection Chamber. Zurot w kierunku audialności wykorzystującej nowinki technologiczne zdaje się upisywać w model wędrującego trójkąta Pleszczyńskiego. Odbiorca zyskuje możliwość komunikacji nie tylko z urządzeniem, ale przede wszystkim - z dziełem, jego światem przedstawionym. Dźwięk, zgodnie z tezą Onga, „wciela” słuchacza w opowieść. Elementy słuchowiska interaktywnego, analogicznie jak składowe wędrującego trójkąta oddziałują na siebie, determinują się wzajemnie i są z sobą nierozerwalne; scenariusz słuchowiska został dostosowany do warunków interaktywnego silnika historii, ten zaś pozwala wypełnić warianty akcji świata przedstawionego. Słuchowisko interaktywne daje szanse na rozwój zarówno umiejętności interpretacyjnych, jak i zasobów poznawczych słuchacza, który staje się bohaterem uwikłanym w akcję. Michela Addis dostrzegła, że

taka interpretacja uwidacznia aktyune role odgrywane przez podmiot i przedmiot u momencie konsumpcji, ponieważ oba przynoszą odmienny i fundamentalny układ u złożone doświadczenie konsumenta: aktywność jednostki wyraża się u subiektywnej interpretacji przedmiotu, podczas gdy działanie tego ostatniego wyraża się przez jego wkład u doświadczenie pod względem treści ${ }^{48}$.

${ }_{46}$ E. Aarseth, op. cit., s. 12.

${ }^{47}$ R. Kluszczyński, Teoretyczno-kulturowe i filozoficzne konteksty sztuki interaktywnej [w:] Interaktywne media sztuki, red. A. Porczak, Wydawnictwo Akademii Sztuk Pięknych im. Jana Matejki, Kraków 2009, s. 23.

${ }^{48} \mathrm{M}$. Addis, New technologies and cultural consumption - edutainment is born!, European Journal of Marketing, vol. 39, issue: 7/8, 2005, https://doi.org/10.1108/03090560510601734 (dostęp: 


\section{Eliza Matusiak}

Trudno w chwili, kiedy słuchowiska interaktywne rozpoczynają ekspansję rynku interaktywnej sztuki dźwiękowej dzięki silnemu rozwojowi wirtualnych asystentów, formułować precyzyjne wnioski o ich znaczeniu na polu sztuki interaktywnej sensu largo. Jednakże ów potencjał zdaje się coraz silniej zarysowywać w obliczu zurotu audytywnego. Fakt, że to właśnie BBC podjęło się próby opracowania innowacyjnego twórczego podejścia do sztuki teatru uyobraźni pozwala domniemywać, iż interaktywność może stać się integralną składową audialnych tekstów kultury, a słuchowiska będą już nie tylko skończonymi dziełami, a podatnymi na przeobrażenia dyspozytywami.

\section{Bibliografia}

Aarseth E.J., Cybertekst. Spojrzenia na literaturę ergodyczna, przeł. M. Tabaczyński, Korporacja Halart, Kraków-Bydgoszcz 2014.

Addis M., New technologies and cultural consumption - edutainment is born!, „European Journal of Marketing" 2005, vol. 39, issue 7/8, s. 729-736.

Albińska K., Kilka uwag o przeobrażeniach środowiska medialnego wspótczesnego radiostuchacza. Szkic przeglądowy, „Media i Społeczeństwo: medioznaustwo, komunikologia, semiologia, socjologia mediów" 2011, nr 1, s. 77.

Bachura J., Odsłony wyobraźni. Wspótczesne stuchowiska radiowe, Wydawnictwo Adam Marszałek, Toruń 2012.

Bachura-Wojtasik J., Literatura audialna między fikcja a niefikcją. „Upowieściowienie” dokumentu a narracje fikcyjne [w:] Między sztuka a codziennością. W stronę nowej syntezy (1), red. M. Hopfinger, Z. Ziątek, T. Żukouski, Instytut Badań Literackich PAN, Warszawa 2016.

Bachura-Wojtasik J., Odsłony wyobraźni. Współczesne stuchowiska radiowe, Wydaunictwo Adam Marszałek, Toruń 2012.

Chung H., Iorga M., Voas J., Lee S., Alexa, Can I Trust You?, https://www.ncbi.nlm.nih.gov/ pmc/articles/PMC5714311/ (dostęp: 08.11.2019).

Czarnek-Wnuk P., Tradycyjne rozgłośnie radiowe $w$ mediach społecznościowych, „Media Kultura - Komunikacja Społeczna" 2016, nr 12/4, s. 41-50.

Gołaszeuska M., Estetyka pięciu zmysłów, Wydawnictuo Naukoue PWN, Warszawa-Kraków 1997.

Hopfinger M., Literatura i media, Oficyna Naukowa, Warszawa 2010.

Jenkins H., Kultura konwergencji. Zderzenie starych i nowych mediów, Wydaunictwa Akademickie i Profesjonalne, Warszawa 2007.

Kluszczyński R.W., Film - wideo - multimedia. Sztuka ruchomego obrazu w erze elektronicznej, Wydawnictuo Rabid, Kraków 2002, s. 31.

Kluszczyński R., Teoretyczno-kulturowe i filozoficzne konteksty sztuki interaktywnej [w:] Interaktywne media sztuki, red. A. Porczak, Wydawnictwo Akademii Sztuk Pięknych im. Jana Matejki, Kraków 2009.

08.11.2019). Tłum. ułasne [E.M.]. Zapis oryginalny: „Such interpretation highlights the active roles played by the subject and the object at the moment of consumption, as both bring different and fundamental contributions to the complex experience of the consumer: the individual's activity is expressed by his subjective interpretation of the object, while the activity of the latter is expressed by its contribution to the experience in terms of content". 
Kowalska A., Uczestnik kultury - nowy czytelnik [w:] Między sztuka a codziennością. W stronę nowej syntezy (1), red. M. Hopfinger, Z. Ziątek, T. Żukouski, Instytut Badań Literackich PAN, Warszawa 2016.

Krzemińska W., Krzemińska A., Ekspansja nowych form komunikacyjnych w środowisku dźwięhowym człowieka [w:] Przestrzenie wizualne i akustyczne człowieka. Antropologia audiowizualna jako przedmiot i metoda badań, red. A. Janiak, W. Krzemińska, A. Wojtasik-Tokarz, Wydawnictuo Naukowe Dolnośląskiej Szkoły Wyższej Edukacji TWP, Wrocław 2007.

Lisouska-Magdziarz M., Metodologia badań nad mediami - nurty, kierunki, koncepcje, nowe wyzwania, „Studia Medioznawcze” 2013, nr 2, s. 27-42.

Maryl M., Pozorne otwarcie hipertekstu. Model komunikacyjny hiperprozy, http://rcin.org.pl/ Content/65710/WA248_84421_maryl-pozorne_o.pdf (dostęp: 08.11.2019).

Ong W.J., Oralność i piśmienność. Stowo poddane technologii, przeł. J. Japola, Redakcja Wydawnictu Katolickiego Uniwersytetu Lubelskiego, Lublin 1992.

Pisarski M., Hipertekst i hiperfikcja [w:] Liternet.pl, red. P. Marecki, Wydawnictwo Rabid, Kraków 2003.

Pisarski M., Kartografowie i kompilatorzy. Pót żartem, pót serio o praktyce i teorii hiperfikcji w Polsce [w:] Liternet.pl, red. P. Marecki, Wydawnictwo Rabid, Kraków 2003.

Pleszczyński J., Dźwięk i muzyka: między racjomorficznością a racjonalnościa [w:] Media multimodalne. Zagadnienia ogólne i teoretyczne. Multimodalność mediów drukowanych, red. I. Hofman, D. Figura-Kępa. T. 1. Wydawnictuo Uniwersytetu Marii Curie-Skłodouskiej, Lublin 2018.

Pleszkun-Olejniczakowa E., Muzy rzadko się do radia przyznaja. Szkice o stuchowiskach i reportażach radiowych, Primum Verbum, Łódź 2012.

Płażewski J., Język filmu, Wydawnictwa Artystyczne i Filmowe, Warszawa 1961.

Prajzner K., Tekst jako świat i gra. Modele narracyjności w kulturze współczesnej, Wydawnictwo Uniwersytetu Łódzkiego, Łódź 2009.

Rogers F., Sharapan H., Special Issue on Counseling and Children's Play, „Elementary School Guidance \& Counseling”, 1993, vol. 28, no. 1.

Siwak W., Audiosfera na przełomie stuleci [w:] Nowe media $w$ komunikacji społecznej w XX wieku. Antologia, red. M. Hopfinger, Oficyna Naukowa, Warszawa 2005.

Szeja J.Z., Tworzenie rzeczywistości wirtualnej [w:] Między sztuka a codziennościa. W stronę nowej syntezy (1), red. M. Hopfinger, Z. Ziątek, T. Żukouski, Instytut Badań Literackich PAN, Warszawa 2016. 